\title{
GENETIC POLYMORPHISM OF WHITE BLOOD CELL GLUCOSE DEHYDROGENASE IN JAPANESE
}

\author{
Yoshio Kera, Kichihei Yamasawa, and Setsuo Komura \\ Department of Legal Medicine, Kyoto Prefectural University of Medicine, \\ Kamikyo-ku, Kyoto 602, Japan
}

\begin{abstract}
Summary Genetic polymorphism of the glucose dehydrogenase in white cells extracts from random adult Japanese was investigated using polyacrylamide gel isoelectric focusing or agarose gel isoelectric focusing, followed by a specific zymogram technique. Three common phenotypes, which might correspond to GDH 1, GDH 2 and GDH 2-1 reported by King and Cook (1981), were observed at the $\mathrm{p} I \mathrm{~s}$ between $\mathrm{pH}$ 6.56-6.76 on the gel. No phenotypes with GDH 3 component were detected so far. The allele frequency of $G D H^{3}$ may be very low among Japanese. The results of family study suggest that these phenotypes are inherited in the autosomal codominant trait. The allele frequencies were $G D H^{1}=0.522$ and $G D H^{2}=0.478$.
\end{abstract}

\section{INTRODUCTION}

Glucose dehydrogenase [GDH, EC 1.1.1.47], a microsomal enzyme, is identical with hexose-6-phosphate dehydrogenase (H6PD). It oxidize glucose, glucose-6phosphate, galactose-6-phosphate and 2-deoxyglucose-6-phosphate utilizing as a coenzyme either nicotinamide adenine dinucleotide (NAD) or nicotinamide adenine dinucleotide phosphate (NADP). In mammalian tissues GDH is distinguishable from glucose-6-phosphate dehydrogenase [G6PD, EC 1.1.1.49] in several properties as subcellular localization, genetic trait, molecular weight, electrophoretic mobility, substrate specificity and immunochemical precipitation or inactivation (Metzger et al., 1964, 1965; Shaw, 1966; Ohno et al., 1966; Beutler and Morrison, 1967; Kimura and Yamashita, 1972; Srivastava et al., 1972; Blume et al., 1975).

King and Cook (1981) have demonstrated genetic polymorphism of GDH using various tissue extract samples in a population of unrelated White British people. Six phenotypes determined by three alleles $\left(G D H^{1}, G D H^{2}\right.$ and $\left.G D H^{3}\right)$ at an autosomal locus were detected by a polyacrylamide gel isoelectric focusing (PAGIEF) followed by a zymogram technique for the developing the enzyme activity on the gel. They have suggested that GDH is also polymorphic in Indians, Chinese, Black Africans, Finns, Greeks and Burmese. Recently Abe et al. (1982)

Received June 30, 1982 
examined post-morten liver extract samples in Japanese, and described that no phenotypes with GDH 3 component were observed. In order to make it easy to investigate this polymorphism on a large scale in various population groups, an utilization of samples prepared from white blood cells seems to be necessary and useful. We reported here GDH polymorphism in the Japanese population using white blood cells extracts as the enzyme sources. Both methods of PAGIEF and agarose gel isoelectric focusing (AGIEF) were used in this study.

\section{MATERIALS AND METHODS}

\section{Sample preparation}

Whole blood samples from 296 unrelated healthy Japanese people and 13 matings with 21 children were collected using $5 \mathrm{~mm} \mathrm{Na}$-EDTA or $13 \mathrm{~mm}$ trisodium citrate as anticoagulants. The buffy coat from $20 \mathrm{ml}$ of whole blood was collected and transferred into a $10 \mathrm{ml}$ plastic test tube. This sample contained a small amount of red blood cells. To remove this red blood cells, $3 \mathrm{ml} \mathrm{of} 0.2 \% \mathrm{NaCl}$ was added to the tube and mixed well. After $30 \mathrm{sec}, 3 \mathrm{ml}$ of $1.6 \% \mathrm{NaCl}$ was added to the mixture, followed by a centrifugation. These procedures were repeated four times. One hundred $\mu$ ll of cold distilled water (or $0.02 \mathrm{~m}$ phosphate buffer containing $1 \%$ Triton $\mathrm{X}-100, \mathrm{pH} 7.5$ ) was added to a final pellet of white blood cells, placing the tube at $-80^{\circ} \mathrm{C}$, rapidly freezing and thawing three times, and centrifuging. The supernatant was used as the enzyme source.

\section{Isoelectric focusing}

Twenty-five $\mu$ l of white blood cells extract was applied onto the gel surface with a sample applicator of paper $(5 \times 10 \mathrm{~mm})$. The isoelectric points in the gel were determined using the Isoelectric Focusing Calibration Kit pH 5-10.5 (Pharmacia). Isoelectric focusings were performed using two different gel plates and conditions. (1) Polyacrylamide gel plate was prepared according to Hobart (1979) but $1 \mathrm{ml}$ of Ampholine pH 3.5-10 (LKB), $0.3 \mathrm{ml}$ of Ampholine pH 5-8 and $0.3 \mathrm{ml}$ of Ampholine $\mathrm{pH}$ 7-9 were used. Isoelectric focusing was carried out for $3.5 \mathrm{hr}$ at a constant power of $10 \mathrm{~W}\left(1,200 \mathrm{~V}\right.$ maximum) with a coolant temperature of $4^{\circ} \mathrm{C}$. Sample applicators were removed after $90 \mathrm{~min}$. Electrode solutions were $1 \mathrm{M}_{3} \mathrm{HO}_{4}$ (anode) and $1 \mathrm{M} \mathrm{NaOH}$ (cathode). (2) Agarose gel plate $(123 \times 136 \times 1 \mathrm{~mm})$ consisted of $0.18 \mathrm{~g}$ of Agarose IEF (Pharmacia), $2.16 \mathrm{~g}$ of D-sorbitol, $1.2 \mathrm{ml}$ of Pharmalyte $\mathrm{pH} \mathrm{5-8} \mathrm{(Pharmacia)} \mathrm{and} 16.2 \mathrm{ml}$ of distilled water. Isoelectric focusing was carried out for $2 \mathrm{~h}$ at a constant power of $7.5 \mathrm{~W}\left(1,500 \mathrm{~V}\right.$ maximum) at $8^{\circ} \mathrm{C}$. Sample applicators were removed after $1 \mathrm{hr}$. Electrode solutions were $0.05 \mathrm{M} \mathrm{H}_{2} \mathrm{SO}_{4}$ (anode) and $1 \mathrm{M} \mathrm{NaOH}$ (cathode).

\section{Zymogram technique}

Each of GDH or G6PD activities on the gel was developed according to Harris and Hopkinson (1976) with minor modifications. 


\section{Neuraminidase treatment}

One $U$ of neuraminidase, lyophilized powder purified from Arthrobactor ureafaciens (Nakarai Chemicals Ltd., Japan) was added to $100 \mu$ of extract sample, followed by an incubation at $8^{\circ} \mathrm{C}$ overnight for $17-18 \mathrm{hr}$.

\section{RESULTS AND DISCUSSION}

In the case of using white blood cells extracts from healthy individuals, three GDH phenotypes were observed by AGIEF (Fig. 1a). The isoelectric points (pIs) of a basic, an acidic and an intermediate types were calibrated to be respectively $\mathrm{pH}$ 6.66-6.76, pH 6.56-6.66 and $\mathrm{pH}$ 6.56-6.76. Each of the basic and the acidic types consisted of 1 major and 2 minor isozyme bands. The intermediate type had 4 or 5 bands. The difference of $\mathrm{p} I \mathrm{~s}$ of among the isoprotein bands in each types was calibrated to be $0.03-0.04 \mathrm{pH}$ unit. The same samples were also subjected to PAGIEF and the similar banding profiles of GDH activity were observed (Fig. 1b). In the sample extraction, the addition of Triton X-100 to the white cells pellet did not affect isozyme pattern and it gave slightly higher intensity of isozyme profile in a comparison to the addition of distilled water. Samples, which were stored for a long term and repeatedly used, caused the original patterns to smear and developed strong anodal repeats. The difference of $\mathrm{p} I \mathrm{~s}$ between the original pattern
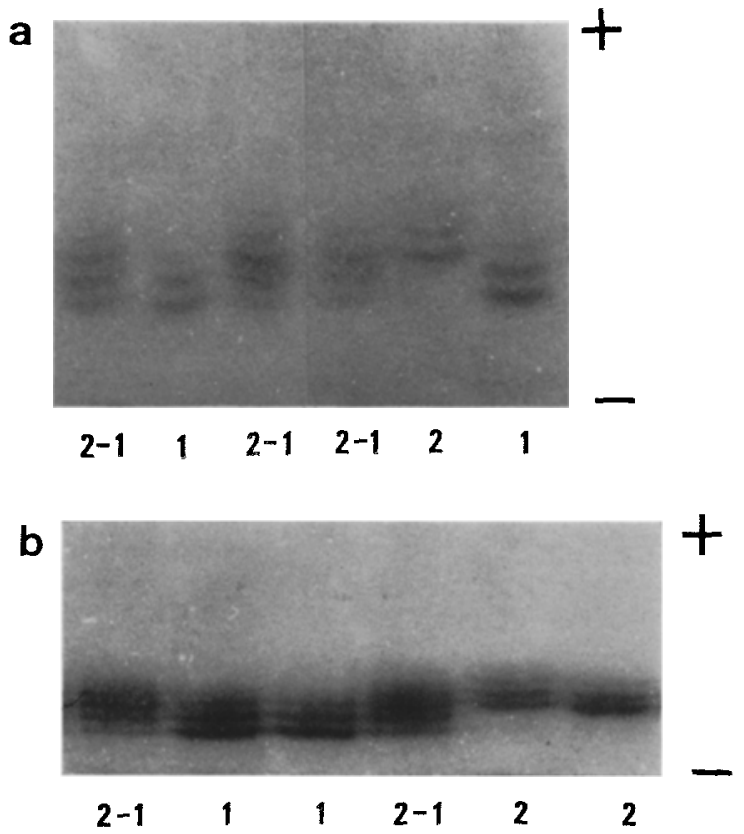

Fig. 1. Photographs of three GDH phenotypes run by AGIEF (a) and PAGIEF (b). 


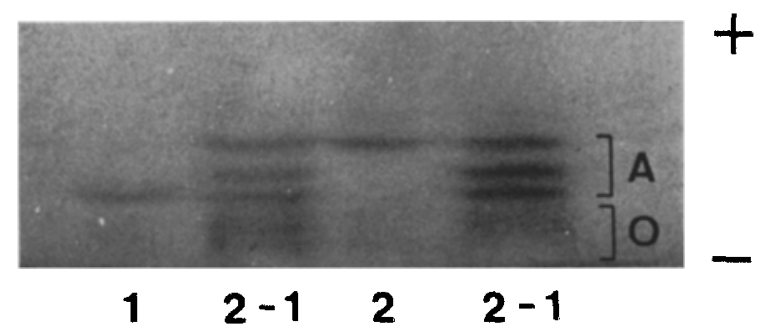

Fig. 2. Photograph showing the anodal repeats $(A)$ and the original patterns $(O)$ of three GDH phenotypes run by PAGIEF.

and the anodal repeat was $0.3-0.4 \mathrm{pH}$ unit in each type. In the patterns of anodal repeats, each of the basic and the acidic types consisted of a single major isozyme bands and the intermediate type had three bands. These pattern seemed to be characteristic of a dimeric protein with two alleles (Fig. 2). Preliminarily, red blood cells hemolysates were used as an enzyme source. No GDH isozyme was detected on the gal by AGIEF or PAGIEF. After AGIEF or PAGIEF, the technique of G6PD staining was also applied to the gel (not shown). The staining profiles suggested that red cells hemolysate showed only G6PD and white cells extract had both GDH and G6PD, and that $\mathrm{p} / \mathrm{s}$ of G6PD was lower than those of GDH. These results were coincident with the previous studies (Shaw, 1966; Ohno et al., 1966). Therefore, these GDH patterns were not contaminated by G6PD.

In the previous investigation (King and Cook, 1981), using liver or placental extracts, GDH 1, GDH 2 and GDH 3 were homozygotes and each of which was a single major isozyme. GDH 2-1, GDH 3-1 and GDH 3-2 each had three isozyme bands in heterozygous form. GDH $1+1-$ consisted of 2 bands was observed in white cells or placental extracts, and it was not a constant characteristic of placental samples since different extracts from the same placenta could be typed as GDH 1 or GDH $1+1-$ (King and Cook, 1981). On the other hand, in the present study, each of the basic and acidic types which seemed to be homozygote by the family study had a microheterogeneous form. The microheterogeneous forms seemed to be constant characteristics. For, samples repeatedly obtained from a same individual in the different days always gave an identical isozyme pattern in each types. The microheterogeneity might exist only in white cells extract. As these microheterogeneity did not reduce or change even after the treatment with neuraminidase, these were not due to unequal contents of sialic acid in isoproteins (not shown).

If symbols of the alleles or phenotypes designated by King and Cook (1981) were used, the basic, the acidic and the intermediate types might correspond to GDH 1, GDH 2 and GDH 2-1, respectively. A family study was carried out to ascertain genetic basis (Table 1). The results were not contradictory to the hypothesis that these phenotypes were inherited in the autosomal codominant trait. The 
Table 1. Distribution of GDH phenotypes in 13 matings with 21 children.

\begin{tabular}{|c|c|c|c|c|c|c|c|}
\hline \multirow{3}{*}{ Parental types } & \multirow{3}{*}{$\begin{array}{l}\text { No. of } \\
\text { matings }\end{array}$} & \multicolumn{6}{|c|}{ No. of children types } \\
\hline & & \multicolumn{2}{|c|}{1} & \multicolumn{2}{|c|}{$2-1$} & \multicolumn{2}{|c|}{2} \\
\hline & & $0^{3}$ & 우 & $0^{7}$ & 우 & $0^{7}$ & 우 \\
\hline $1 \times 1$ & 1 & 1 & 1 & 0 & 0 & 0 & 0 \\
\hline $1 \times 2-1$ & 1 & 0 & 0 & 1 & 0 & 0 & 0 \\
\hline $2-1 \times 1$ & 2 & 1 & 0 & 1 & 0 & 0 & 0 \\
\hline $2-1 \times 2-1$ & 4 & 1 & 0 & 3 & 3 & 0 & 0 \\
\hline $2-1 \times 2$ & 1 & 0 & 0 & 0 & 0 & 1 & 0 \\
\hline $2 \times 2-1$ & 3 & 0 & 0 & 2 & 2 & 2 & 0 \\
\hline $2 \times 2$ & 1 & 0 & 0 & 0 & 0 & 2 & 0 \\
\hline
\end{tabular}

Table 2. Distribution of GDH phenotypes and allele frequencies in the Japanese population.

\begin{tabular}{ccccc}
\hline & \multicolumn{3}{c}{ Phenotypes } & Total \\
\cline { 2 - 5 } & 1 & $2-1$ & 2 & 74 \\
\hline Observed No. & 88 & 160 & 322 \\
Expected No. & 27.3 & 49.7 & 23.0 & 100.0 \\
\hline
\end{tabular}

Allele frequencies. $G D H^{1}=0.522, G D H^{2}=0.478 . \quad \chi^{2}=0.006$, d.f. $=1,0.90<\mathrm{p}<0.95$.

Table 3. Allele frequencies of $\mathrm{GDH}$ in various population.

\begin{tabular}{llrrrrr}
\hline Population & \multicolumn{1}{c}{ Samples } & $\mathrm{n}$ & Common & $\begin{array}{c}\text { Second } \\
\text { common a }\end{array}$ & $\begin{array}{c}\text { Third } \\
\text { common }\end{array}$ & Authors \\
\hline White British & Lid, Pl e, WBC & 373 & 0.723 & 0.194 & 0.083 & King and Cook (1981) \\
Caucasians & $\mathrm{Sag}$ & 190 & 0.755 & 0.245 & - & Tan and Ashton (1976) \\
Chinese & $\mathrm{Sa}$ & 34 & 0.706 & 0.294 & - & Tan and Ashton (1976) \\
Japanese & $\mathrm{Sa}$ & 104 & 0.659 & 0.341 & - & Tan and Ashton (1976) \\
Japanese & $\mathrm{Li}$ & 125 & 0.520 & 0.480 & - & Abe et al. (1982) \\
Japanese & $\mathrm{WBC}$ & 322 & 0.522 & 0.478 & - & Present study \\
\hline
\end{tabular}

a $G D H^{1}$ or $S g d^{1}$. ' $G D H^{2}$ or $S g d^{2}$. ' $G D H^{3}$. ¿ $\mathrm{Li}=$ livers. e $\mathrm{Pl}=$ placentas. $f \mathrm{WBC}=$ white blood cells. $\mathrm{g} \mathrm{Sa}=$ saliva.

distribution of GDH phenotypes and allele frequencies in the Japanese population were given in Table 2. The population materials consisted of 296 unrelated healthy Japanese people and parents $(\mathrm{N}=26)$ from family materials. The observed number fit to those expected on Hardy-Weinberg equilibrium. Allele frequencies of $G D H^{1}$ and $G D H^{2}$ were estimated at 0.522 and 0.478 , respectively. These values of allele 
frequencies are nearly equal to another report on the Japanese population in Tokyo Metropolis, using post-morten liver extracts (Abe et al., 1982). In the present study, only two alleles were detected and no phenotypes with GDH 3 component was observed so far. These results are also coincident with the another report on Japanese (Abe et al., 1982). The allele frequency of $G D H^{3}$ might be very low among Japanese people.

The allele frequency of $G D H^{1}$ in the Japanese population was lower than that in the White British (King and Cook, 1981) shown in Table 3. Tan and Ashton (1976) reported an autosomal H6PD (GDH) polymorphism in human saliva by using polyacrylamide gel electrophoresis. In which, the allele frequencies among Japanese people in Hawaii were different from those in the present study. These differences may be due to racial or regional, methodological differences.

\section{REFERENCES}

Abe, K., Akiyarna, K., and Nakamura, S. 1982. Polymorphism of glucose dehydrogenase in liver in Japanese. J. Tokyo Wom. Med. Coll. 52: 541-543 (in Japanese).

Beutler, E. and Morrison, M. 1967. Localization and characteristics of hexose-6-phosphate dehydrogenase (glucose dehydrogenase). J. Biol. Chem. 242: 5289-5293.

Blume, K.G., Schmidt, G.M., Heissmeier, H.H., and Löhr, G.W. 1975. Hexose-6-phosphate dehydrogenase from human tissues: an electrophoretic study in health and disease. Experimentia 31: 496-498

Harris, H. and Hopkinson, D.A. 1976. Handbook of Enzyme Electrophoresis in Human Genetics. North-Holland Publishing Company, Amsterdam.

Hobart, M.J. 1979. Genetic polymorphism of human plasminogen. Ann. Hum. Genet. 42: 419423.

Kimura, H. and Yamashita, M. 1972. Studies on microsomal glucose-6-phosphate dehydrogenase of rat liver. J. Biochem. 71: 1009-1014.

King, J. and Cook, P.J.L. 1981. Glucose dehydrogenase polymorphism in man. Ann. Hum. Genet. 45: 129-134.

Metzger, R.P., Wilcox, S.S., and Wick, A.N. 1964. Studies with rat liver glucose dehydrogenase. J. Biol. Chem. 239: 1769-1.772.

Metzger, R.P., Wilcox, S.S., and Wick, A.N. 1965. Subcellular distribution and properties of hepatic glucose dehydrogenase of selected vertebrates. J. Biol. Chem. 240: 2767-2771.

Ohno, S., Payne, H.W., Morrison, M., and Beutler, E. 1966. Hexose-6-phosphate dehydrogenase found in human liver. Science 153: 1015-1016.

Shaw, C.R. 1966. Glucose-6-phosphate dehydrogenase: Homologous molecules in der mouse and man. Science 153: 103-1015.

Srivastava, S.K., Blume, K.G., and Beutler, E. 1972. Immunological difference between glucose6-P dehydrogenase and hexose-6-P dehydrogenase from human liver. Nature New Biol. 238: 240-241.

Tan, S.G. and Ashton, G.C. 1976. An autosomal glucose-6-phosphate dehydrogenase (hexose6-phosphate dehydrogenase) polymorphism in human saliva. Hum. Hered. 26: 113-123. 